\title{
THE INFLUENCE OF EXOCRINE PANCREATIC INSUFFICIENCY IN THE FORMATION OF OSTEOPENIA IN PATIENTS WITH PRIMARY OSTEOARTHRITIS
}

\author{
Liliya S. Babinets, Iryna M. Halabitska, Iryna 0. Borovyk, Olena V. Redkva, Halyna M. Sasyk \\ I. HORBACHEVSKY TERNOPIL NATIONAL MEDICAL UNIVERSITY, TERNOPIL, UKRAINE
}

\begin{abstract}
The aim: Make complex study of bone density in patients with primary osteoarthritis and exocrine pancreatic insufficiency and patients with primary osteoarthritis without exocrine pancreatic insufficiency.

Materials and methods: There were examined 140 patients with primary osteoarthritis without exocrine pancreatic insufficiency and combination osteoarthritis and exocrine pancreatic insufficiency. Diagnosis of osteoarthritis was based on diagnostic X-Ray criteria - according to J.H. Kellgren and J.S. Lawrence. The level of exocrine pancreatic insufficiency was based on result of Elisa test. State of mineral bone density was examined by using dual-photon densitometry.

Results: It was established that there was a progressive, statistical, significant increase of mineral density of bone tissue in the 1-st group patients with osteoarthritis. Patients in the 2-nd group, with osteoarthritis in the comorbidity with exocrine pancreatic insufficiency, the densitogram rates were statistically significantly lower than in patients in the 1-st group. Conclusions: The changes of bone tissue can be explained by the formation of trophological insufficiency as a result of exocrine pancreatic insufficiency. One of the symptoms of trophic failure is bone and mineral changes, in particular, the decrease of bone density.
\end{abstract}

KEY WORDS: osteoarthritis; exocrine pancreatic insufficiency; mineral density of bone tissue

Wiad Lek. 2020;73(10):2238-2240

\section{INTRODUCTION}

Study of bone tissue state is very topical in case of combination of osteoarthritis and osteoporosis. These two disorders are very common, with leading prevalence. Each of them has negative influence on ability to work and may lead to long-term disability. Studies also found a high incidence of the gastrointestinal tract diseases in patients with osteoarthritis, especially those that are accompanied by a violation of the excretory insufficiency of pancreas. The excretory insufficiency of pancreas in patients with primary osteoarthritis is formed at the comorbid pathologies and as a result of long-term treatment of osteoarthrosis using the non-steroidal anti-inflammatory drugs, steroids, chondroprotectors and chondrostimulators etc. Inflammation plays significant part in the pathogenesis of osteoarthritis. The main mechanism of cartilage degradation are production of proinflammatory cytokines (IL- $1 \beta$, IL- 6, FNP- $\alpha$, etc.). They release enzymes that damage collagen (collagenase, elastase, peptidase) and proteoglycans (metalloproteinases, stromelysin, cathepsins) and activate proteolytic activity. This leads to increased destruction of hyaluronic fibers and a decrease cartilage regeneration [1-7].

\section{THE AIM}

Make complex study of bone density in patients with primary osteoarthritis and exocrine pancreatic insufficiency and patients with primary osteoarthritis without exocrine pancreatic insufficiency.

\section{MATERIALS AND METHODS}

There were examined 67 ambulatory patients with primary osteoarthritis (1-st group) and 73 patients with osteoarthritis in the comorbidity with exocrine pancreatic insufficiency (2-nd group). Average age was (52.7 \pm 3.5 ) year old (from 29 to 76$), 84(60.0 \%)$ women and 56 men (40.0 \%). Control group consisted of 30 healthy people.

Excluding criteria: oncological diseases, acute and exacerbation of chronic disease of vital organs, severe diabetes mellitus type 2 , diabetes mellitus type 1 , gastric and duodenal ulcers, viral hepatitis and cirrhosis, Crohn's disease, ulcerative colitis, cystic fibrosis.

Diagnosis of primary osteoarthritis was determined based on diagnostic criteria, X-Ray stage - according J.H. Kellgren and J.S. Lawrence.

Degree of exocrine pancreatic insufficiency was verified based on result of fecal elastase-1, which was done by Elisa test.

State of mineral bone density was examined by using dual-photon densitometry. Measured values were analyzed according to the age, gender by densitometer «Lunar» and reflect the healthy population of men and women in Ukraine. 
Table I. Densitometric values in patients with primary osteoarthritis of lumbar spine.

\begin{tabular}{|c|c|c|c|c|c|c|}
\hline \multirow[b]{2}{*}{ Comparison group } & \multirow{2}{*}{$\begin{array}{l}\text { The zone of } \\
\text { CT indicators } \\
\text { determination }\end{array}$} & \multicolumn{5}{|c|}{ CT scan } \\
\hline & & $\begin{array}{c}\text { BMD, } \\
\mathrm{g} / \mathrm{cm}^{2}(\mathrm{n}=140)\end{array}$ & $\begin{array}{l}\text { T, standard unit } \\
(n=140)\end{array}$ & $\begin{array}{c}T, \% \\
(n=140)\end{array}$ & $\begin{array}{l}Z, \text { standard unit } \\
(n=140)\end{array}$ & $\begin{array}{c}Z, \% \\
(n=140)\end{array}$ \\
\hline $\begin{array}{l}\text { 1-st group } \\
(\mathrm{n}=67)\end{array}$ & L1-L4 of spine & $\begin{array}{l}1,18 \pm \\
0,01^{*}\end{array}$ & $\begin{array}{c}-0,07 \pm \\
0,09^{*}\end{array}$ & $\begin{array}{c}99,29 \pm \\
0,96^{*}\end{array}$ & $\begin{array}{l}0,22 \pm \\
0,24^{*}\end{array}$ & $\begin{array}{c}102,97 \pm \\
1,97^{*}\end{array}$ \\
\hline $\begin{array}{l}\text { 2-nd group } \\
\qquad(\mathrm{n}=73)\end{array}$ & L1-L4 of spine & $\begin{array}{c}0.99 \pm \\
0,01^{*} \\
\mathrm{p}_{1-2}<0,05\end{array}$ & $\begin{array}{c}-1,70 \pm \\
0,02^{*} \\
\mathrm{p}_{1-2}<0,05\end{array}$ & $\begin{array}{c}86,35 \pm \\
0,26^{*} \\
\mathrm{p}_{1-2}<0,05\end{array}$ & $\begin{array}{c}-1,40 \pm \\
0,10^{*} \\
p_{1-2}<0,05\end{array}$ & $\begin{array}{c}82,59 \pm \\
1,06^{*} \\
\mathrm{p}_{1-2}<0,05\end{array}$ \\
\hline
\end{tabular}

Note: * all indicators are statistically significant in relation to the reference database Lunar;

$\mathrm{p}_{1-2}$ - statistically significant differences in the data between the study groups.

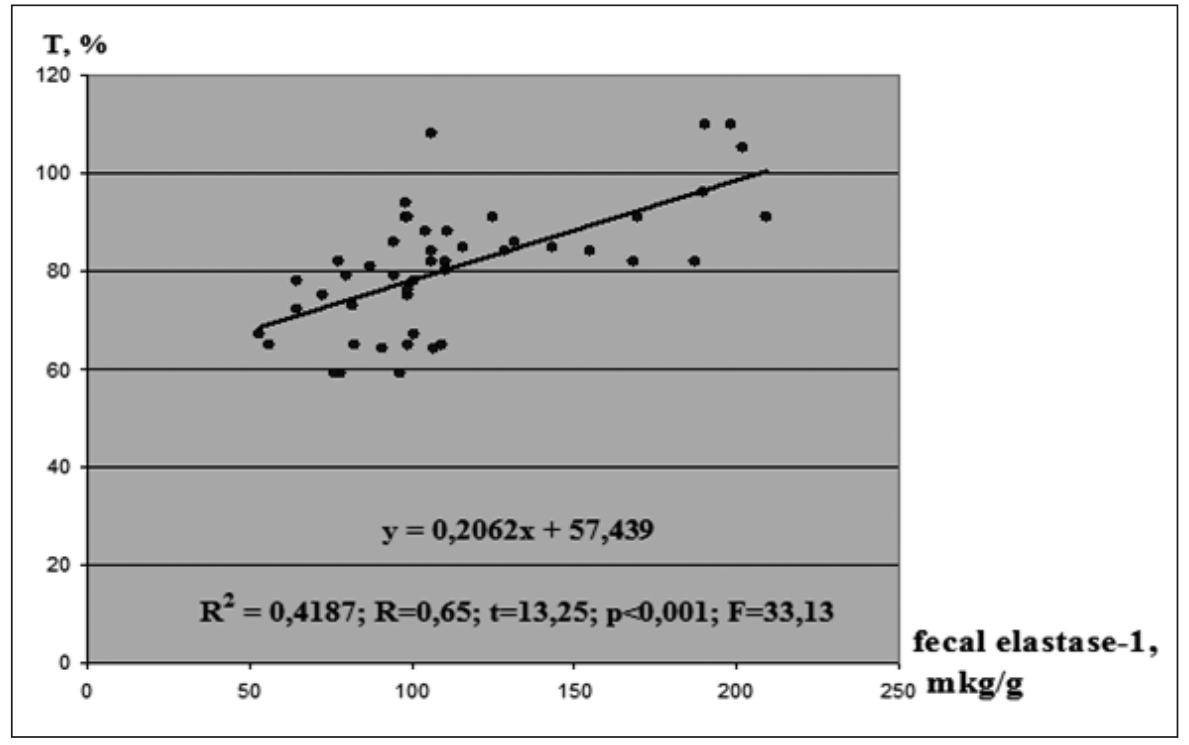

Fig. 1. The dependence of the BMD of patients with osteoporosis from exocrine pancreatic dysfunction by the indicator $\mathrm{T}(\%)$ on the level of fecal a-elastase.

\section{RESULTS AND DISCUSSION}

Analysis of obtained fecal elastase- 1 values has shown the presence of exocrine pancreatic dysfunction in both investigated groups - $(153.83 \pm 5.34) \mathrm{mkg} / \mathrm{g}$ and $(58.65 \pm 4.73)$ $\mathrm{mkg} / \mathrm{g}$ respectively in comparison with control group $(213 \pm 6.29) \mathrm{mkg} / \mathrm{g}$ as well as statistically accurate lower level of fecal elastase in second group compared to the first one $(\mathrm{p}<0.05)$.

It has proved the presence of deeper exocrine pancreatic dysfunction in osteoarthritis with concomitant gastrointestinal disorders and exocrine pancreatic dysfunction as well as presence of mild exocrine pancreatic dysfunction in 1-st group of people diagnosed with isolated osteoarthritis without gastrointestinal disorders $(\mathrm{p}<0.05)$.

It supports the idea about necessity and importance of this problem investigation and taking into account the presence of exocrine pancreatic dysfunction in both groups for effective complex of patients rehabilitation who were diagnosed with osteoarthritis and concomitant gastrointestinal disorders and osteoarthritis without concomitant gastrointestinal disorders.

Table I shows obtained results of our investigated densitometric values of bones in patients with primary osteoarthritis without gastrointestinal disorders and in patients with primary osteoarthritis with gastrointestinal disorders. Investigated area - lumbar spine.
Obtained densitometrical values showed that the patients with primary osteoarthritis without gastrointestinal disorders (1-st group) are more likely to develop of mineral density of bone tissue, densitometrical values were statistically more significant in comparison with referent base of Lunar $(p<0.05)$ however were in normal reference range according to the age.

In the 2-nd group which the patients had primary osteoarthritis with gastrointestinal disorders the values of densitometry were statistically significantly lower compared to referent base of Lunar and reflected Osteopenia, stage $2(\mathrm{p}<0.05)$.

In Figure 1 it is showing the regression and correlation analysis between mineral density of bone tissue and indicator $\mathrm{T}$ in patients with concomitant exocrine pancreatic dysfunction and fecal elastase level.

Completed analysis established the significant correlation between mentioned above indicators and has proved important role of pancreas function in trophic insufficiency development especially in osteopenia for people diagnosed with osteoarthritis. Linear trend and formula reflect direct correlation and give us an ability to predict the decrease of bones mineral density according to fecal elastase level.

It shows the necessity to include pancreatic functional state in development of complex therapy for patients with combination of osteoarthritis and concomitant gastrointestinal disorders too. 
Sum up the results of research, we can talk about the negative influence of exocrine pancreatic insufficiency to the of bone mass.

Densitogram in 1-st group patients shows the tendency of patients with primary osteoarthritis to increase mineral density of bone tissue. The results were statistically significantly higher in relation to the referent base Lunar $(p<0,05)$, but were within the age range.

Patients in 2-nd group, with primary osteoarthritis with gastrointestinal disorders, the densitogram rates were statistically significantly lower than in patients 1-st group, and lower in relation to the reference base of Lunar and were at the 2 st level of osteopenia. $(\mathrm{p}<0.05)$. Completed correlation and regression analysis established significant correlation between bone mineral density and fecal elastase value and also has proved importance of functional state of pancreas in trophic insufficiency development and osteopenia for patients with osteoarthritis

\section{CONCLUSIONS}

1. More sever exocrine pancreatic dysfunction in case of osteoarthritis and concomitant gastrointestinal disorder and mild exocrine insufficiency of pancreas in patient with osteoarthritis without gastrointestinal disorder were proved.

2. In patients with primary isolated osteoarthritis mineral bone density has been improving densitometrical values were statistically significantly higher than Lunar reference values.

3. Patients with primary osteoarthritis and gastrointestinal diseases characterized by severe exocrine pancreatic dysfunction were diagnosed with 2-rd stage of osteopenia.

4. Completed correlation and regression analysis established significant correlation between bone mineral density and fecal elastase value and also has proved importance of functional state of pancreas in trophic insufficiency development and osteopenia for patients with osteoarthritis $(\mathrm{p}<0.05)$.

\section{REFERENCES}

1. Babinets L., Halabitska I., Kotsaba Y. et al. The effect of the proteolisis' system activity for the trophological status of patients with osteoarthritis and exocrine insufficiency of pancreas. Wiad. Lek. 2018; 71 (2 pt 1): 273276.

2. Waldstein W., Perino G., Gilbert S.L. et al. OARSI osteoarthritis cartilage histopathology assessment system: A biomechanical evaluation in the human knee. J Orthop Res 2016; 34: 135-140.
3. Arden N., Nevitt M. Osteoarthritis: Epidemiology Best Practice and Research: Clinical Rheumatology, 2006, 20 (1): 3-25.

4. Glyn-Jones S., Palmer A.J., Agricola R. et al. Osteoarthritis. The Lancet. 2015; 386 (9991):376-387. doi: 10.1016/50140-6736(14)60802-3.

5. Wang X., Hunter D., Xu J., Ding C. Metabolic triggered inflammation in osteoarthritis. Osteoarthritis and Cartilage. 2015;23 (1): 22-30.

6. Singh J., NoorbaloochiS., Macdonald R. etal. Chondroitinfor osteoarthritis (2015) Cochrane Database of Systematic Reviews, 2017 (6), art. no. CD005614.

7. Ding Y., Wang L., Zhao Q., et al. MicroRNA-93 inhibits chondrocyte apoptosis and inflammation in osteoarthritis by targeting the TLR4/ $\mathrm{NF}-\mathrm{kB}$ signaling pathway. International Journal of Molecular Medicine. 2019;43(2):779-790. doi:10.3892/ijmm.2018.4033.

Research topic: 0118U000361, Comprehensive approach to the control of symptoms, direct and distant prognosis in conditions of comorbid pathology in the clinic of internal diseases and the practice of a family.

\section{ORCID and contributionship:}

Liliya S. Babinets: 0000-0002-0560-1943 A,B,C,D,E,F

Iryna M. Halabitska: 0000-0002-9028-7230 A,B,C,D,E,F

Iryna O. Borovyk: 0000-0003-0114-2935 B,C,D

Olena V. Redkva: 0000-0002-3572-1583 $3^{C, D}$

Halyna M. Sasyk: 0000-0002-9640-9155 E,F

\section{Conflict of interest:}

The Authors declare no conflict of interest.

\section{CORRESPONDING AUTHOR}

\section{Liliya S. Babinets}

I. Horbachevsky Ternopil National Medical University

Kupchyns'ky 14 Str., Ternopil, Ukraine, 46400;

tel: +380673520743,

e-mail: lilyababinets@gmail.com

Received: 03.06 .2020

Accepted: 26.08 .2020

A - Work concept and design, B - Data collection and analysis, C - Responsibility for statistical analysis,

D-Writing the article, $\mathbf{E}$-Critical review, $\mathbf{F}$ - Final approval of the article 